\title{
The Continued Development of the Third-generation Shallow Water Wave Model "SWAN"
}

Annual report 2001

Report 05-01

TüUdelft

Delft University of Technology

Faculty of Civil Engineering and Geosciences

October 2001

Fluid Mechanics Section

Commissioned by: Office of Naval Research 


\title{
The Continued Development of the Third-generation Shallow Water Wave Model "SWAN"
}

\author{
Annual report 2001 \\ Model development and support \\ Leo Holthuijsen, Nico Booij, IJsbrand Haagsma, Annette Kieftenburg, Ekaterini \\ Kriezi $^{1}$
}

October 2001

Report No. 05-01

Commissioned by: $\quad$ Office of Naval Research

${ }^{1}$ Faculty of Civil Engineering and Geosciences, Department of Civil Engineering, Section of Fluid Mechanics, Delft University of Technology, P.O.Box 5048, 2600 GA Delft, NL 


\title{
The Continued Development of the Third-generation Shallow Water Wave Model "SWAN"
}

\author{
Leo Holthuijsen \\ Department. Of Civil Engineering \\ Delft University of Technology \\ Stevinweg 1, $2628 \mathrm{CN}$, Delft the Netherlands \\ phone: ++31-15-2784803 fax: ++31-15-2784842 email: 1.holthuijsen@ct.tudelft.nl \\ Award \#: N00014-97-0113 \\ http://swan.ct.tudelft.nl
}

\section{LONG-TERM GOALS}

The long-term goal of this effort is to provide a commonly accepted third-generation wave model for shallow water to the international community of scientists and engineers for the purpose of basic research and operational wave computations.

\section{OBJECTIVES}

The main objective is to support and assist the development, validation and verification of the SWAN model and its use in operational conditions. The development is based on new scientific insights in the evolution of waves in shallow water. The verification and validation is based on field observations and laboratory experiments supplemented with numerical experiments. Operational use is supported with firstline assistance and diagnostics.

\section{APPROACH}

The development of the SWAN model is envisioned as a community effort of the wave modelers presently working in this field of technology, most of whom coordinate their efforts in an international forum called the WISE group (Waves in Shallow Environments).

We provide support and assistance to the ONR-designated investigators. We assist in the installation of SWAN under conventional operating systems (also as a sub-model in larger systems of models such as atmospheric and ocean circulation models). The complete and detailed documentation (about 120 pages) has been supplemented with introductory documentation. Questions of users are answered and errors are located and repaired. Updated program codes are communicated to all registered users. This support is operating through electronic-mail facilities.

This approach is essentially a continuation of the development of the SWAN model over the years 1992 - 1996 by J.A. Battjes, L.H. Holthuijsen and N. Booij and their Ph.D. students. This consists of designing, implementing and testing a fully spectral third-generation wave model for shallow water with a fully implicit propagation scheme. Battjes supervises the scientific developments, Booij supervises the numerical developments. Holthuijsen is responsible for project management and overall supervision. In addition, IJ.G. Haagsma, A.T.M.M. Kieftenburg and E.E. Kriezi carry out the upgrading of the computer code as regards system requirements as well as regards scientific and numerical aspects and they provide first-line support for the users. 


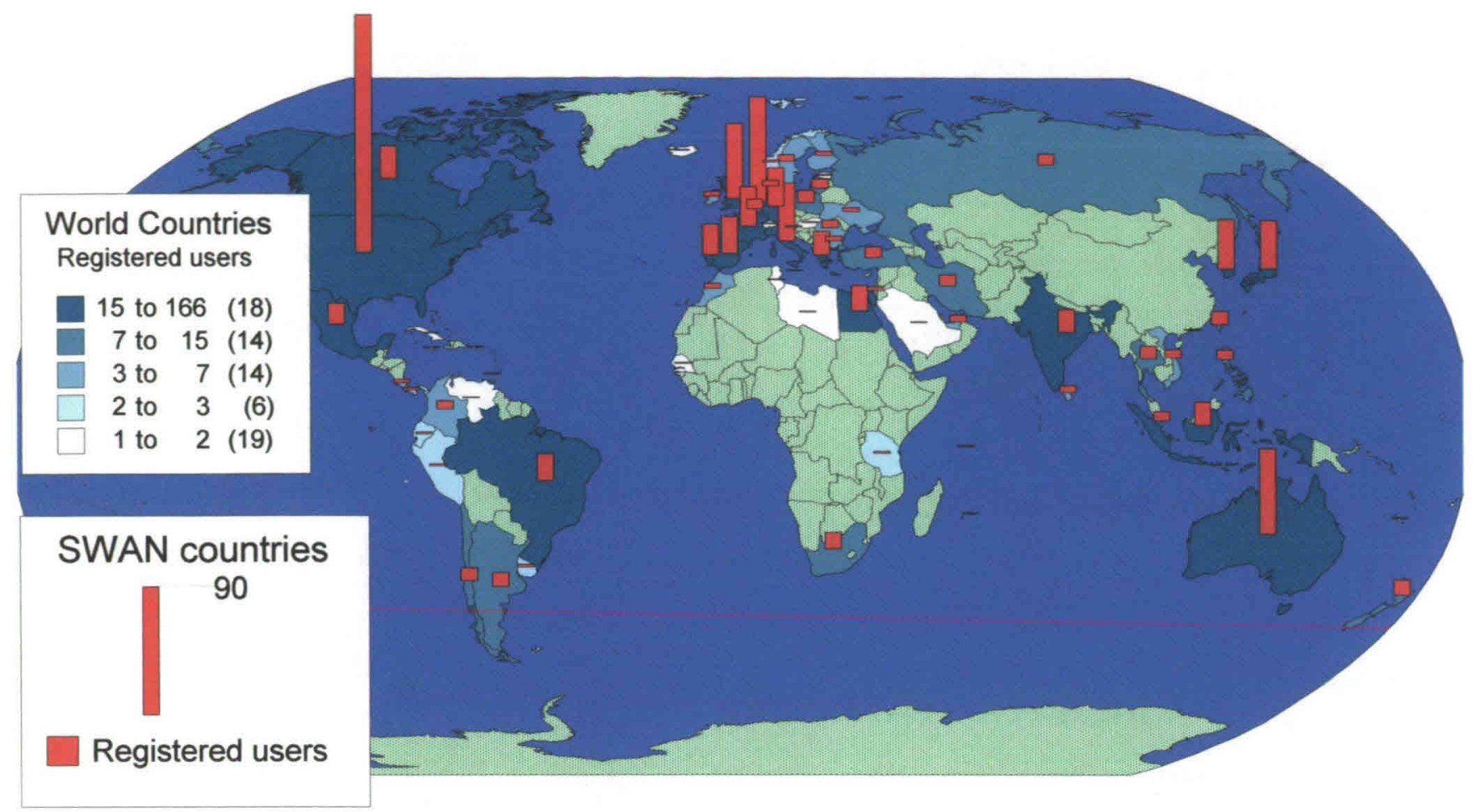

Figure $1 \quad$ Distribution of SWAN users in the world in July 2001.

\section{WORK COMPLETED}

A new version of SWAN, SWAN 40.11 Cycle III (to extend the present Cycle II with oceanic options) was released on October $26^{\text {th }}, 2000$. Compared to the previous authorized version, SWAN 40.01, this new release:

- $\quad$ permits wave propagation with highly reduced diffusion (using a third-order propagation scheme for non-stationary computations and a second-order scheme for stationary computations developed in the AWPP program (by J. Kaihatu, E. Rogers, H. Petit, N. Booij and L. Holthuijsen),

- $\quad$ permits wave propagation on the globe (oceans) with the basic model equation formulated and implemented in terms of longitude and latitude (optional),

- $\quad$ can dampen the garden sprinkler effect with a diffusion term (default),

- $\quad$ can reflect waves against obstacles (command option)

- $\quad$ allows nesting in WAVEWATCH III (data transfer only; physics presently being tested).

All bug-fixes for the previous release are included.

\section{Support and assistance}

a) The SWAN homepage on the internet has been regularly updated. Coding bugs which are discovered in the authorized version of SWAN, and their fixes, are published on this site. The discussion group of SWAN on the website is operational.

b) The SWAN code (40.11, and previous versions) has been downloaded by approximately 940 institutes from over 70 countries.

c) In the report period 103 queries of users about SWAN installation have been answered: general information (30), program bugs (21), installation (21), code (7) and usage (24). 
d) The testing of the SWAN code with the Lahey Fortran 95 compiler version 5.0 (severest level) was continued. SWAN Cycle III (40.11) requires a Fortran90 compiler as the transition to Fortran90 has been initiated.

User documentation:

Several of the existing subroutines have been adapted to the SWAN programming protocol.

User support, diagnostics and repairs:

a) Several (minor) errors in the new release have been detected. They are published on the SWAN home page, describing the impact and (possible) solutions.

b) The updating of the system documentation (headers of the subroutines) has continued.

\section{RESULTS}

Improvement of model technology

a) Scattered reflection against obstacles has been added to the presently operational specular reflection (not Bragg scattering or bottom scattering). See Figure 2.

b) A modification of the white-capping source term has been implemented. It reproduces a generic laboratory experiment of $\mathrm{M}$. Donelan (where wind sea is generated in the presence of a following swell) but it fails to reproduce an equally generic experiment of Mitsuyasu (where wind sea is generated in the presence of an opposing swell). A field equivalent of the experiment of Donelan (Haringvliet) is being investigated with this new formulation. Ocean-scale applications give unrealistic results.

c) The effect of swell on wind generation has been parameterized in an experimental version of SWAN. The laboratory experiments of Donelan and Mitsuyasu can now both be explained.

d) A multiple DIA approximation of the quadruplet wave-wave interaction (six quadruplets) has been included in an experimental version of SWAN with the support of N. Hashimoto (short visit from Japan). Experiments look promising

e) A code for exact calculations of the quadruplet wave-wave interactions has been acquired from $\mathrm{N}$. Hashimoto. During a short visit of Hashimoto this code has been included in an experimental version of SWAN. During that visit the code has been modified to obtain more stable results than with previous versions of that code. The results of a real 2D case in Lake George (Australia) are significantly better (at the price of very large computing effort) than with the default DIA approximation.

f) The transition from Fortran77 to Fortran90 of the SWAN code is continuing. The full transition depends on funding outside the present project.

g) Numerical experiments (funded by the Dutch Ministry of Public Works) have shown the dominant character of the numerical limiter in SWAN (taken from the WAM model). Alternatives have been tried but failed to give satisfactory results. The (de-)activation of the limiter for the source terms will be user controlled in the next release of SWAN. Some improvements in shallow water can thus be achieved.

h) The formulations of WAVEWATCH III for representing the physical processes of generation and dissipation in deep water have been implemented in an experimental version of SWAN. They are being tested.

i) The model for depth-induced breaking in SWAN has been extended with the model of Baldock (to better estimate the fraction of breakers) and the maximum possible wave height (for a given depth) 

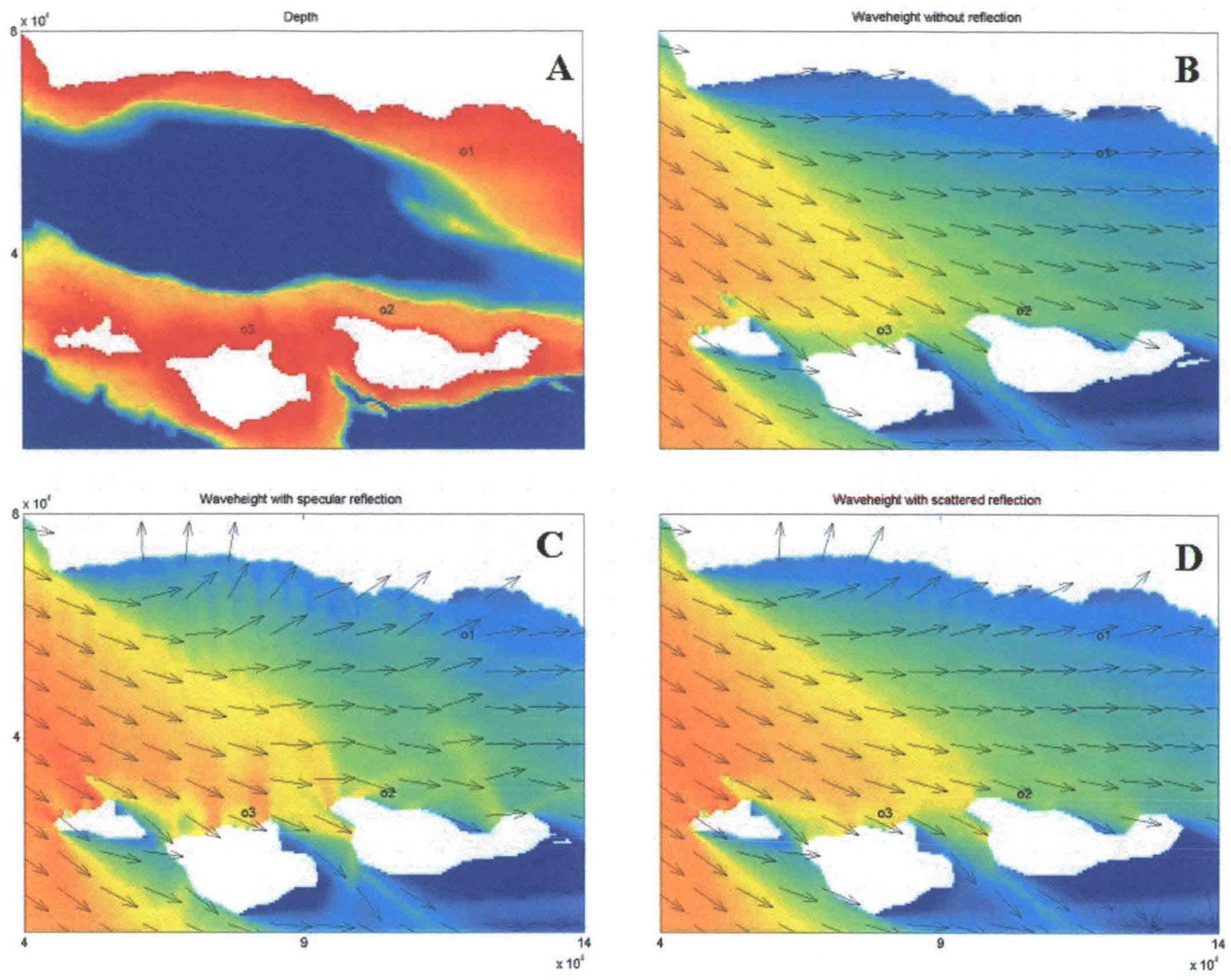

Figure 2

Wave reflection in the Santa Barbara Channel (USA, panel A).The wave height and the wave directions are significantly affected by reflection, particularly near the coastline and close to the islands (compare panels $B$ with $C$ and D; reflection coefficients are deduced from buoy measurements in the channel). Both effects are in agreement with recent measurements. With scattered reflection (panel D), SWAN gives a smoother wave field than with specular reflection (panel C).

has been made dependent on wave steepness (based on Battjes and Stive). Both modifications improve the performance of SWAN in the surf zone.

j) Diffraction based on a phase-decoupled approach has been included successfully in an experimental version. See Figure 3.

k) The boundary conditions for the wave- induced set-up have been improved.

l) The convergence of the solver for the wave-induced set-up has been improved.

m) The development of a $4^{\text {th }}$-generation version of SWAN (a bi-spectral version) has been initiated (outside this project). 

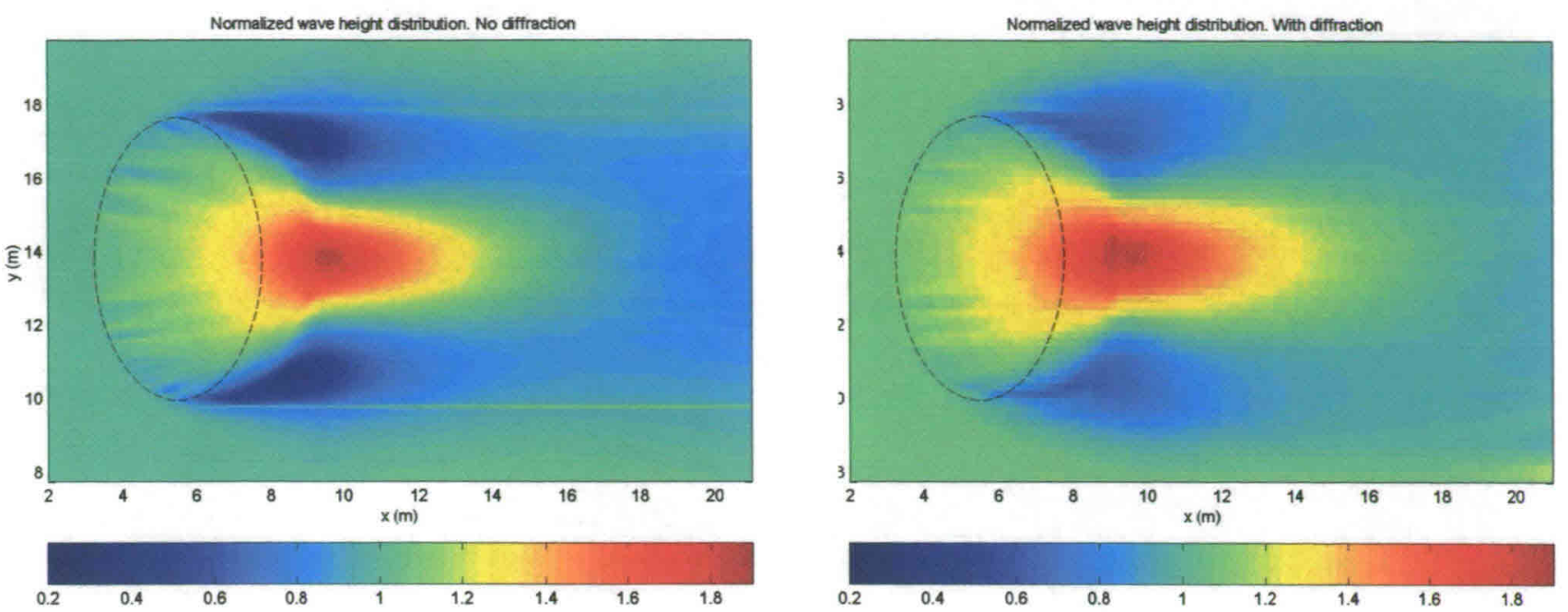

Figure 3

Monochromatic, uni-directional waves travel from left to right through a wave tank across an elliptical shoal located at the left side of the tank. Colors show wave height normalized with the incident wave height: without diffraction (left), with diffraction (right). The wave field with diffraction is considerably smoother than without diffraction and in better agreement with observations.

\section{IMPACT/APPLICATION}

SWAN provides scientists with a common platform for their research of the generation, propagation and dissipation of wind surface waves in shallow water. It facilitates the integration of these aspects and avoids the need to develop supplementary models in each individual research project. With the support provided here, the results of such projects will be implemented in the fully operational SWAN model thus serving the community in general. It provides a common standard for coastal applications, and is accepted by a large number of institutions worldwide: SWAN has now been introduced to about 940 institutes from all over the world by registered users.

\section{TRANSITIONS}

The SWAN model is available free of charge to anyone. It can be downloaded from the SWAN website. Its use is supported by the original authors under this project. SWAN is aimed at operational use by such government agencies as army and navy, national weather services and others. Also private industry is using SWAN, mostly to determine the coastal wave climate for the purpose of design of structures and off-shore operations.

\section{RELATED PROJECTS}

Considerable efforts are being carried out by others to further develop the SWAN model. In the USA this is coordinated mostly through the AWPP program of ONR. In Europe, similar efforts (on a smaller scale) are carried out by groups of investigators funded by the EC and by national governments (notably in the Netherlands, Germany and England). The nature of these efforts is both theoretical and empirical and require extensive field work and computer experiments. The level of funding is several million US dollars per year. 


\section{PUBLICATIONS}

Andorka Gal, J.H., L.H. Holthuijsen, J.C.M. de Jong and A.T.M.M. Kieftenburg, 1998, Wave transformation near a quasi-1D coast, 26th Int. Conf. Coastal Engng., Copenhagen,150-160

Booij, N., L.H. Holthuijsen and R.C. Ris, 1996, The "SWAN" wave model for shallow water, Proc. 25th Int. Conf. Coastal Engng., Orlando, 668-676

Booij, N., L.H. Holthuijsen and R. Padilla-Hernandez, 1997, A nonstationary, parametric coastal wave model, Conf. Coastal Dynamics '97, Plymouth, 99-107

Booij, N., L.H. Holthuijsen, N. Doorn and A.T.M.M. Kieftenburg, 1997, Diffraction in a spectral wave model, Proceedings 3rd International Symposium on Ocean Wave Measurement and Analysis, WAVES'97, ASCE, 243-255

Booij, N., L.H. Holthuijsen and R. Padilla-Hernandez, 1997, Numerical wave propagation on a curvi-linear grid, Proceedings 3rd International Symposium on Ocean Wave Measurement and Analysis, WAVES'97, ASCE, 286-294

Booij, N., L.H. Holthuijsen and R.C. Ris, 1998, Shallow water wave modelling, Oceanology International 98, The Global Ocean, Brighton, Conference Proceedings, 3, 483-491

Booij, N., L.H. Holthuijsen and IJ.G. Haagsma, 1998, Comparing the second-generation HISWA wave model with the third-generation SWAN wave model, 5th International Workshop on Wave Hindcasting and Forecasting, Jan. 27-30, 1998, Melbourne, Florida, 215-222

Booij, N., R.C. Ris and L.H. Holthuijsen, 1999, A third-generation wave model for coastal regions, Part I, Model description and validation, J.Geoph.Research, 104, C4, 7649-7666

Booij, N and L.H. Holthuijsen, 2000, The effect of swell on the generation and dissipation of waves, $4^{\text {th }}$ Int. Symposium on Ocean Wave Measurements and Analysis, San Fransisco, abstract submitted

Cavaleri, L. and L.H. Holthuijsen, 1998, Wave modelling in the WISE group, Proc. 26th Int. Conf. Coastal Engng., Copenhagen, 498-508

Holthuijsen, L.H., N. Booij and R.C. Ris, 1993, A spectral wave model for the coastal zone, Proceedings 2nd International Symposium on Ocean Wave Measurement and Analysis, New Orleans, Louisiana, July 25-28, 1993, New York, 630-641

Holthuijsen, L.H., N. Booij and R. Padilla-Hernandez, 1997, A curvi-linear, third-generation coastal wave model, Conf. Coastal Dynamics '97, Plymouth, 128-136

Holthuijsen, L.H., N. Booij, R. Ris, J.H. Andorka Gal and J.C.M. de Jong, 1997, A verification of the thirdgeneration wave model "SWAN" along the southern North Sea coast, Proceedings 3rd International Symposium on Ocean Wave Measurement and Analysis, WAVES'97, ASCE, 49-63

Holthuijsen, L.H., R.C. Ris and N. Booij, 1998, A verification of the third-generation wave model SWAN, 5th International Workshop on Wave Hindcasting and Forecasting, Jan. 27-30, 1998, Melbourne, Florida, 223-230

Holthuijsen, L.H., N. Booij and IJ.G. Haagsma, 1998, Comparing $1^{\text {st }}-, 2^{\text {nd }}-$ and $3^{\text {rd }}$-generation coastal wave modelling, 26th Int. Conf. Coastal Engng., Copenhagen, 140-149

Holthuijsen, L.H. and N. Booij, 2000, Oceanic and near-shore whitecapping effects in SWAN, $\sigma^{\text {th }}$ Int. Workshop on Wave Hindcasting and Forecasting, Monterey, 362-368

Holthuijsen, L.H, R.C. Ris, N. Booij and E.Cecchi, 2000, Swell and whitecapping, 27th Int. Conf. Coastal Engng., Sydney, Proc. 27th Int. Conf. Coastal Engng., Sydney, 346-354

Holthuijsen, L.H., N. Booij and J.A. Battjes, 2000, Multiple-scale wave modelling with SWAN, $4^{\text {th }}$ Int. Conference on Coastal Dynamics 2001, Lund, Sweden, 335-344

Holthuijsen L.H., A. Herman, N. Booij and W. Cieslikiewicz, 2001, experimental mild-slope diffraction in $\mathrm{n}$ the SWAN wave model, 28th Int. Conf. Coastal Eng., accepted for presentation 
Padilla-Hernandez, R., P. Osuna, J. Monbaliu and L. Holthuijsen, 1998, Intercomparing third-generation wave model nesting, 5th International Workshop on Wave Hindcasting and Forecasting, Jan. 27-30, 1998, Melbourne, Florida, 102-112

Ris, R.C., L.H. Holthuijsen and N. Booij, 1994, A spectral model for waves in the near shore zone, Proc. 24th Int. Conf. Coastal Engng, Kobe, Oct. 1994, Japan, 68-78

Ris, R.C. and L.H. Holthuijsen, 1997, Modelling of current induced wave-blocking in a spectral wave model, $8^{\text {th }}$ International Biennal Conference on Physics of Estuaries and Coastal Seas, J. Dronkers and M.B.A.M. Scheffers (eds.), The Hague, 139-144

Ris, R.C., N. Booij and L.H. Holthuijsen, 1999, A third-generation wave model for coastal regions, Part II: Verification, J.Geoph.Research, 104, C4,7667-7681

Rogers, E., J. Kaihatu, H. Petit, N. Booij and L. Holthuijsen, Diffusion Reduction in an Arbitrary Scale Third Generation Wind-Waves Model, Coastal Engineering, in press 


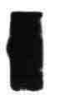

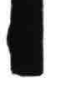

I

I

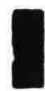

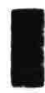

